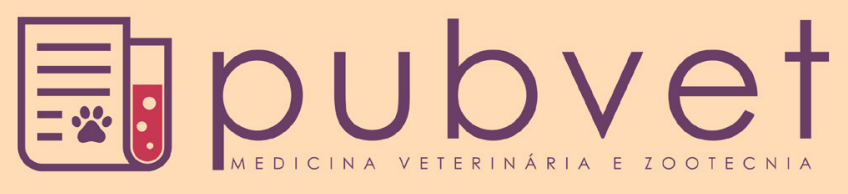

HTTP://DX.DOI.ORG/10.22256/PUBVET.VI1 IN7.737-743

\title{
Desempenho e viabilidade econômica de bovinos precoces submetidos a diferentes níveis de suplementos
}

\author{
Luiz Carlos Pereira ${ }^{1 *}$, Rodrigo Gonçalves Mateus ${ }^{2}$, Alysson Martins Wanderley ${ }^{3}$, João \\ Victor de Souza Martins ${ }^{4}$, Douglas Gomes Vieira ${ }^{4}$, Lucas Gomes da Silva ${ }^{5}$, Euler Cassio \\ Alcantara Cruz ${ }^{5}$, Cristiano Marcelo Espínola Carvalho ${ }^{6}$

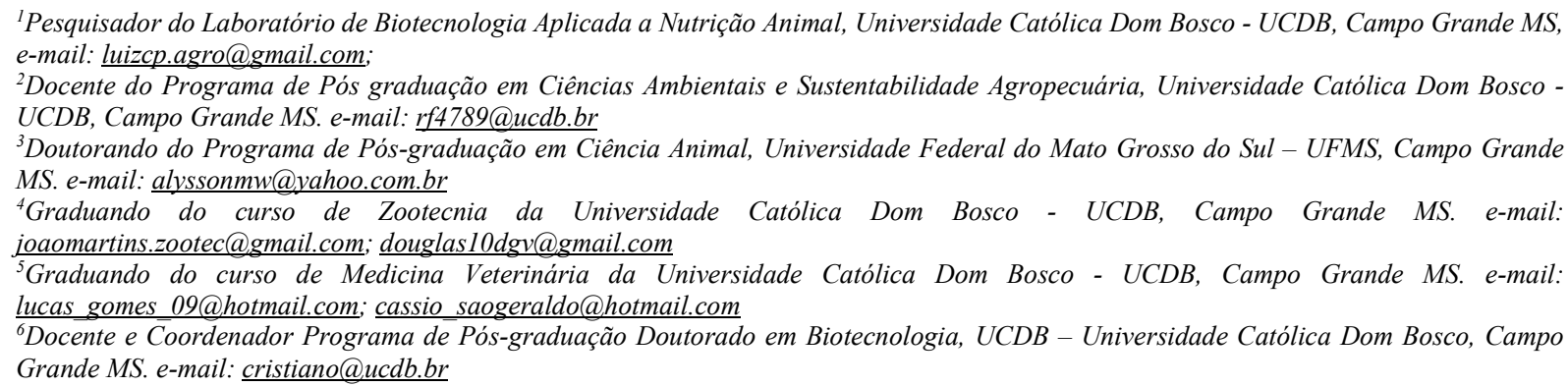

RESUMO. Objetivou-se neste estudo avaliar o efeito de dois protocolos de suplementação proteica energética no desempenho e viabilidade econômica de bezerros nelore não castrados ao desmame a terminação a pasto. Foram utilizados 40 bovinos da raça Nelore com 8 meses de idade, peso médio 285,16 $\pm 22,74 \mathrm{Kg}$, pertencentes à Fazenda Fronteira município de Porto Murtinho, Mato Grosso do Sul, avaliados entre maio de 2015 e setembro de 2016. Analise de desempenho dos animais apresentou efeito, entre os tratamentos para peso final, o ganho médio total e ganho de peso médio diário. Os bovinos suplementados com Protocolo 2 consumiram maior quantidade de matéria seca $(807,57 \mathrm{~kg})$ que os animais do Protocolo 1 (427,03 kg). Com este nível de consumo de matéria seca também houve aumento na quantidade de proteína bruta fornecida para o Protocolo $2 \mathrm{em}$ $320,17 \mathrm{~kg}$. A maior receita total observada foi Protocolo $1(\mathrm{R} \$ 2.868,90)$ este resultado está associado ao peso final superior e ao rendimento de carcaça de 52,6\% após o abate, embora o Protocolo 2 tenha apresentada maior rendimento de carcaça (54\%). Conclui-se que A suplementação do Protocolo 1 foi mais eficiente para desempenho, no entanto a receita total foi insuficiente para pagar os custos de produção, gerando uma rentabilidade negativa devido ao gasto com suplementação no período experimental.

Palavras chaves: bovino de corte, ganho de peso, suplementação a pasto

\section{Performance and economic viability of young bulls submitted to different supplements}

ABSTRACT. The objective of this study was to evaluate the effect of two energy protein supplementation protocols on performance and economic viability of Nellore bulls calves from weaning to pasture finishing. Nellore calves with 8 months of age, mean weight $285.16 \pm 22.74 \mathrm{~kg}$, belonging to the Fronteira Farm municipality of Porto Murtinho, Mato Grosso do Sul, were evaluated between May 2015 and September 2016. Analysis, between the treatments for final weight, mean total gain and average daily weight gain. Steers supplemented with Protocol 2 consumed more dry matter $(807.57 \mathrm{~kg})$ and Protocol 1 animals $(427.03 \mathrm{~kg})$. As this level of dry matter consumption there was also an increase in the amount of crude protein supplied to Protocol 2 in $320.17 \mathrm{~kg}$. The highest total income 
observed was Protocol 1 ( $\mathrm{R} \$ 2,868.90)$, this result is associated with the higher final weight and the carcass yield of 52.6\% after slaughter, although Protocol 2 presented higher carcass yield (54\%). It is concluded that the supplementation of Protocol 1 was more efficient for performance; however the total revenue was insufficient to pay the production costs, generating a negative profitability due to the expense of supplementation in the experimental period.

Keywords: Beef cattle, grass supplementation, weight gain

\section{Rendimiento productivo y viabilidad económica de bovinos precoces sometidos a diferentes niveles de suplementación}

RESUMEN. En este estudio se evaluó el efecto de dos protocolos de suplementación proteica energética en el desempeño y viabilidad económica de bovinos no castrados al destete y engordados a pasto. Se utilizaron 40 becerros de la raza Nelore con 8 meses de edad, peso promedio 285,16 $\pm 22,74 \mathrm{Kg}$, pertenecientes a la Hacienda Fronteira municipio de Porto Murtinho, Mato Grosso do Sul, evaluados entre mayo de 2015 a septiembre de 2016. Análisis de los rendimientos productivos presentaron efecto entre los tratamientos para el peso final, la ganancia media total y la ganancia de peso diario. Los bovinos suplementados con el protocolo 2 consumieron mayor cantidad de materia seca $(807,57 \mathrm{~kg})$ que los animales del Protocolo 1 (427,03 kg). Con este nivel de consumo de materia seca también hubo aumento en la cantidad de proteína bruta suministrada para el Protocolo 2 en $320,17 \mathrm{~kg}$. El mayor ingreso total observado fue el Protocolo $1(\mathrm{R} \$ 2.868,90)$ este resultado está asociado al peso final superior y al rendimiento de carcasa del 52,6\% después del sacrificio, aunque el Protocolo 2 haya presentado mayor rendimiento de carcasa (54\%). Se concluye que la suplementación del Protocolo 1 fue más eficiente para el rendimiento productivo, sin embargo los ingresos totales fueron insuficientes para pagar los costos de producción, generando una rentabilidad negativa debido al gasto con suplementación en el período experimental.

Palabras clave: Bovino de carne, ganancia de peso, suplementación a pasto

\section{Introdução}

Animais criados exclusivamente a pasto tendem a ter menores rendimentos e uma menor expressão de seu potencial genético. Esse fato se dá devido à baixa ingestão de alimentos oriundos de pastagens de baixa qualidade (Santos et al., 2011, Prado et al., 2010). Desta maneira, a suplementação a pasto se torna uma ferramenta importante no aumento da produtividade por área de pastagem permitindo que os animais expressem seu potencial genético e aumentando a taxa de lotação (Freitas et al., 2005b, Moreira et al., 2006, Santos et al., 2011).

A suplementação alimentar tem o intuito de complementar o valor nutritivo das forragens, a fim de atender as necessidades nutricionais dos animais, podendo deste modo, alcançar o desempenho desejado (Moreira and Prado, 2010, Prado et al., 2010). A resposta adequada à utilização de suplementos é influenciada pela disponibilidade de pasto, composição do suplemento que é utilizado, como é fornecida e potencial genético do animal (Moreira et al., 2006, Prado and Moreira, 2002).

A suplementação de concentrados para animais nas épocas das águas é uma ferramenta que auxilia no manejo do pastejo, aumentando o consumo de nutrientes, e consequentemente a eficiência na utilização da forragem disponível e melhorando o desempenho do animal (Freitas et al., 2005a, Freitas et al., 2005b, Frizzo et al., 2003). Os suplementos concentrados podem diminuir o consumo de forragem, principalmente se tiver características nutricionais iguais ao de pasto. Nas condições de elevado efeito substitutivo, pode haver sobra de forragens, devendo-se promover ajuste ao número de bovinos relacionado em função de massa de forrageiras disponíveis (Hellbrugge et al., 2008).

$\mathrm{O}$ maior índice de deficiência de minerais durante o período de chuva está menor relacionado à concentração de minerais no pasto do que o incremento das necessidades nutricionais de bovinos a pasto. $\mathrm{Na}$ época das chuvas o gado ganha peso mais rápido, devido ao elevado índice 
de proteína e energia que está presente nas pastagens, no período seco isso e aproveitado em menor quantidade (Euclides et al., 1998).

Este trabalho objetivou-se avaliar efeito dois protocolos de suplementação proteica e energética no desempenho e viabilidade econômica de bezerros nelores não castrados do desmame a terminação a pasto.

\section{Material e Métodos}

O experimento foi conduzido na Fazenda Fronteira localizada no município de Porto Murtinho, Mato Grosso do Sul, com 80 bezerros da raça Nelore, não castrados com idade de 8 meses. Os animais apresentaram peso médio inicial de $285,16 \pm 22.74 \mathrm{~kg}$. A suplementação foi realizada entre maio de 2015 e setembro de 2016.

A área experimental apresentava 80 ha, subdividida em 8 piquetes de 10 ha cada, compostas de Panicum maximum cv. Tanzânia. Cada grupo de bezerros foi alojado em áreas vizinhas com quatro piquetes e uma praça de alimentação contenho cocho para suplementação e bebedouro. A fim de minimizar o efeito da forragem os animais foram mantidos em sistema rotacionado de pastejo ( 28 dias de pastejo e 84 de descanso da forragem).

Foram utilizados dois protocolos de suplementação com diferentes quantidades de matéria seca (MS) e proteína bruta (PB) fornecidos uma vez ao dia às 16:00 horas. $O$ delineamento experimental foi inteiramente casualizado com 2 tratamentos (Tratamento 1 Protocolo 1, baixa nível de suplementação no período final de terminação; Tratamento 2 Protocolo 2, alto nível de suplementação no final da terminação) respeitando os princípios básicos da experimentação: repetição, casualização e controle local (Ferreira, 2011).

A dieta composta $2 \%$ alimento proteico e $98 \%$ alimento volumoso (pastagem de Panicum maximum $c v$. Tanzânia) formulado para suprir as exigências nutricionais dos bezerros para um ganho de peso médio diário de $500 \mathrm{~g}$ (NRC, 2000). Foram fornecidas 4 formulações de suplementos em 6 períodos distintos. A composição centesimal dos ingredientes da dieta está na Tabela 1.

Tabela 1. Teores bromatológicos dos suplementos utilizados para cada protocolo.

\begin{tabular}{lcccccc}
\hline Variáveis & Período 1 & Período 2 & Período 3 & Período 4 & Período 5 & Período 6 \\
\hline Protocolo 1 & & & & & & \\
MS (\%) & 88 & 87 & 87 & 87 & 87 & 86 \\
PB (\%) & 25 & 31 & 31 & 31 & 31 & 25 \\
NDT (\%) & 70 & 64 & 64 & 64 & 64 & 70 \\
Quantidade de dias por período & 31 & 183 & 124 & 17 & 44 & 91 \\
Fornecido (Kg) & 0,80 & 0,45 & 0,50 & 0,50 & 1,56 & 2,50 \\
\hline Protocolo 2 & & & & & & \\
MS (\%) & 87 & 87 & 87 & 87 & 88 & 88 \\
PB (\%) & 17 & 24,6 & 24,6 & 24,6 & $59 *$ & $59 *$ \\
NDT (\%) & 70 & 70 & 70 & 70 & 73,6 & 73,6 \\
Quantidade de dias por período & 32 & 182 & 124 & 83 & 53 & 15 \\
Fornecido (Kg) & 1,00 & 0,30 & 0,29 & 1,42 & 8,00 & 10,00 \\
\hline
\end{tabular}

* NNP equiv. Proteína

A cada 60 dias foram realizados mensurações de peso corporal dos animais. Ao final da pesquisa foram calculados os indicadores de desempenho e produtividade: Consumo total e diário de suplemento, ganho de peso médio diário (GMD), ganho de peso médio total (GPT); Índice de Conversão Alimentar (consumo médio de mistura mineral em um período de tempo / ganho de peso médio) utilizados para a identificação da relação do custo/benefício de um determinado suplemento. A metodologia que foi utilizada neste estudo para cálculo de custos de produção (Tabela 2), foi realizada através da divisão de Custo Operacional Efetivo (COE), Custo Operacional Total (COT) e Custo Total (CT), conforme Ferreira et al. (2005). A classificação dos custos, apresentados anteriormente, permitirá identificar os seguintes indicadores de resultado e rentabilidade, no qual servirão de base para a análise dos sistemas de produção, de acordo com a metodologias definidas por Martin et al. (1998) e Lazzarini Neto (1995) de Receita Total (RT). 
Tabela 2. Preço dos suplementos por período

\begin{tabular}{lcccccc}
\hline & Período 1 & Período 2 & Período 3 & Período 4 & Período 5 & Período 6 \\
\hline Protocolo 1 & 1,46 & 1,19 & 1,52 & 1,64 & 1,50 & 1,47 \\
Protocolo 2 & 0,92 & 1,19 & 1,17 & 1,17 & 0,83 & 0,83 \\
\hline
\end{tabular}

Os dados foram submetidos à análise de variância (ANOVA) a 5\% de significância. No caso de ser observada diferença significativa nos resultados, para as características mais relacionadas, utilizando-se o programa estatístico SAS 9.2 (

\section{Resultados e discussão}

Análise de desempenho dos animais apresentou efeito $(\mathrm{P}<0,05)$ entre os tratamentos para peso final (PF), o ganho médio total (GPT) e ganho de peso médio diário (Tabela 3 ).

O peso final (PF) dos bovinos do Protocolo 2 foi $30,16 \mathrm{~kg}$ superior ao Protocolo 1, da mesma forma foi observado para o GPT que foi apresentou ganho 14,61\% superior do Protocolo 2 em relação ao outro tratamento. $\mathrm{O}$ ganho médio diário (GMD) do Protocolo 1 apresentou ganho $14,26 \%$ inferior em relação ao Protocolo 2.
Tabela 3. Avaliação de desempenho de bovinos Nelore suplementados com mistura proteico energética do desmame até a terminação em pastagens de Panicum maximum $\mathrm{cv}$. Tanzânia durante 495 dias

\begin{tabular}{lcccc}
\hline Variáveis & Protocolo 1 & Protocolo 2 & CV & P \\
\hline $\mathrm{N}$ & 40 & 40 & & \\
PI (kg) & 282,23 & 287,51 & 7,30 & 0,279 \\
PF (kg) & $530,14 \mathrm{~b}$ & $560,30 \mathrm{a}$ & 5,84 & 0,001 \\
GPT (kg) & $242,62 \mathrm{~b}$ & $278,07 \mathrm{a}$ & 9,84 & 0,001 \\
GMD (g) & $491 \mathrm{~b}$ & $561 \mathrm{a}$ & 9,84 & 0,001 \\
\hline
\end{tabular}

Peso inicial (PI); Peso médio final (PF); Ganho peso médio total (GPT); Ganho peso médio diário (GMD); Coeficiente de variação (CV); P-Efeito do Tratamento. Médias da mesma linha com letras minúsculas diferentes foram significativa para Tratamento pelo teste Mann-Whitney $(\mathrm{P}<0,05)$.

O consumo total e médio de matéria seca, proteína bruta e NDT foram significativos para efeito $(\mathrm{P}<0,05)$ de tratamento ( $\underline{\text { Tabela } 4})$.

Tabela 4. Avaliação de consumo de bovinos Nelore suplementados com mistura proteico energética do desmame até a terminação em pastagens de Panicum maximum cv. Tanzânia durante 495 dias.

\begin{tabular}{lcccc}
\hline Variáveis & Protocolo 1 & Protocolo 2 & CV & P \\
\hline Consumo total de matéria seca $(\mathrm{kg})$ & 427,03 & 807,57 & 0,001 & 0,001 \\
Consumo total de proteína bruta $(\mathrm{kg})$ & 137,74 & 457,91 & 0,001 & 0,001 \\
Consumo total de NDT (kg) & 330,77 & 668,77 & 0,001 & 0,001 \\
Consumo médio de matéria seca (kg) & 0,863 & 1,631 & 0,001 & 0,001 \\
Consumo médio de proteína bruta (kg) & 0,278 & 0,925 & 0,001 & 0,001 \\
Consumo médio de NDT (kg) & 0,668 & 1,351 & 0,001 & 0,001 \\
ICAMS & 1,771 & 2,923 & 9,59 & 0,001 \\
ICAPB & 0,573 & 1,656 & 10,21 & 0,001 \\
\hline
\end{tabular}

Índice de conversão alimentar da matéria seca (ICAMS). Índice de conversão alimentar da proteína bruta (ICAPB); Coeficiente de variação (CV); P-Efeito do Tratamento. Médias da mesma linha com letras minúsculas diferentes foram significativa para Tratamento pelo teste Mann-Whitney $(\mathrm{P}<0,05)$.

Os bovinos suplementados com Protocolo 2 consumiram maior quantidade de matéria seca $(\mathrm{P}<0,05)$, resultando na elevação na quantidade de proteína bruta fornecida. Contudo o protocolo 1 apresentou uma menor eficiência da conversão alimentar de matéria seca e proteína bruta durante o período experimental. A baixa a baixa conversão da proteína bruta do Protocolo 2 possivelmente deve estar associada as altas concentrações de nitrogênio não proteico (NNP), que não foi metabolizado pelo organismo do animal.
Já a análise do centro de custos identificou a suplementação com maior valor nos custos operacionais dos animais, o Protocolo 2 apresentado um gasto de $\mathrm{R} \$ 127,23$ superior (Tabela 5).

Portanto a maior eficiência do Protocolo 1 na suplementação revelou uma redução do custo de capital em 8,35\%, devido ao menor juros de capital de giro atribuído ao menor valor do gasto com suplemento (Tabela 5). 
Tabela 5. Centro de custo de bovinos Nelore suplementados com mistura proteico energética do desmame até a terminação em pastagens de Panicum maximum cv. Tanzânia durante 495 dias.

\begin{tabular}{lcccc}
\hline Variáveis & Protocolo 1 & Protocolo 2 & CV & P \\
\hline Preço de compra Kg vivo (R\$) & 6,67 & 6,67 & - & - \\
Preço de venda kg carne (R\$) & 9,53 & 9,53 & - & - \\
Sanidade (R\$/animal/período) & 1,97 & 1,97 & - & - \\
Aluguel (R\$/animal/período) & 400,00 & 400,00 & - & - \\
Suplementação (R\$/animal/período) & $711,55 \mathrm{a}$ & $838,78 \mathrm{~b}$ & 0,001 & 0,001 \\
Juros K giro (R\$) & $136,22 \mathrm{a}$ & $151,48 \mathrm{~b}$ & 0,024 & 0,001 \\
K investido (R\$) & 1917,72 & 1882,48 & 7,306 & 0,279 \\
Juros de K (R\$) & 38,54 & 37,83 & 7,306 & 0,279 \\
\hline
\end{tabular}

Coeficiente de variação (CV); P-Efeito do Tratamento. Médias da mesma linha com letras minúsculas diferentes foram significativa para Tratamento pelo teste Mann-Whitney $(\mathrm{P}<0,05)$.

O valor do custo total do Protocolo 1 de R\$ 3.206,01 apresentou diferença significativa $(\mathrm{P}<0,05)$ do Protocolo 2 que obteve valor de $\mathrm{R} \$$ $3.312,85$ (Tabela 6).

A maior receita total observada foi Protocolo 2 ( R \$ 2.885,01) este resultado está associado ao PF superior (Tabela 3 ) e ao rendimento de carcaça de
54\% após o abate. Já o Protocolo 1 apresentou rendimento de carcaça inferior $(52,6 \%)$.

Esses resultados refletem na margem bruta que apurou um valor de $\mathrm{R} \$ 192,91$ e $\mathrm{R} \$ 102,91$ para o Protocolo 2 e Protocolo 1 respectivamente, ou seja, valor associado a maior receita operacional do Protocolo2 durante o período experimental (Tabela 6).

Tabela 6. Viabilidade econômica de bovinos Nelore suplementados com mistura proteico energética do desmame até a terminação em pastagens de Panicum maximum cv. Tanzânia durante 495 dias

\begin{tabular}{|c|c|c|c|c|}
\hline Variáveis & Protocolo 1 & Protocolo 2 & $\mathrm{CV}$ & $\mathrm{P}$ \\
\hline Custo operacional efetivo $\left(\mathrm{R} \$\right.$ animal $\left.^{-1}\right)$ & 1113,52 & 1240,75 & 0,001 & 0,001 \\
\hline Custo operacional total $\left(\mathrm{R} \$\right.$ animal $\left.^{-1}\right)$ & $3031,24 a$ & $3123,23 b$ & 4,511 & 0,006 \\
\hline Custo de capital (R\$) & $174,76 \mathrm{a}$ & $189,61 b$ & 1,524 & 0,001 \\
\hline Custo Total $\left(\mathrm{R} \$\right.$ animal $\left.^{-1}\right)$ & $3206,01 \mathrm{a}$ & $3312,85 b$ & 4,338 & 0,003 \\
\hline Receita Operacional Total $\left(\mathrm{R} \$\right.$ animal $\left.^{-1}\right)$ & $1216,24 b$ & $1433,66^{\mathrm{a}}$ & 9,752 & 0,001 \\
\hline Receita Total $\left(\mathrm{R} \$\right.$ animal $\left.^{-1}\right)$ & $2657,49 b$ & $2885,01^{\mathrm{a}}$ & 5,854 & 0,029 \\
\hline Margem Bruta $\left(\mathrm{R} \$\right.$ animal $\left.^{-1}\right)$ & $102,91 b$ & $192,91^{\mathrm{a}}$ & 86,377 & 0,001 \\
\hline Margem liquida $\left(\mathrm{R} \$\right.$ animal $\left.^{-1}\right)$ & $-373,75 b$ & $-238,22^{\mathrm{a}}$ & 44,993 & 0,001 \\
\hline Retorno econômico ( $\mathrm{R} \$$ animal $^{-1}$ ) & $-548,52 b$ & $-427,83^{\mathrm{a}}$ & 28,223 & 0,001 \\
\hline Ponto de equilíbrio do peso animal (kg) & $636,14 \mathrm{a}$ & $655,45 b$ & 4,501 & 0,006 \\
\hline Preço de nivelamento $(\mathrm{kg}$ & $11,51 \mathrm{~b}$ & $10,96^{\mathrm{a}}$ & 4,652 & 0,001 \\
\hline Lucratividade (\%) & $-20,87 b$ & $-15,07^{\mathrm{a}}$ & 29,732 & 0,001 \\
\hline Rentabilidade (\%) & $-18,08 b$ & $-13,64^{\mathrm{a}}$ & 27,223 & 0,001 \\
\hline Margem Líquida (R \$/kg/ganho) & $-2,32 b$ & $-1,59^{\mathrm{a}}$ & 29,412 & 0,001 \\
\hline
\end{tabular}

Coeficiente de variação (CV); P-Efeito do Tratamento. Médias da mesma linha com letras minúsculas diferentes foram significativa para Tratamento pelo teste Mann-Whitney $(\mathrm{P}<0,05)$.

Contudo os protocolos não apresentaram resultado econômico satisfatório mesmo apresentando diferenças $(\mathrm{P}<0,05)$. Esses resultados indicam que, embora os animais apresentarem bom desempenho, os índices de lucratividade e rentabilidade final foram negativos para os tratamentos avaliados. Reflexo do alto custo com a suplementação durante o período de avaliação. Outro fator importante é falto de ajuste da dieta, com baixos níveis de fontes de nitrogênio orgânico que favorece a síntese de proteína microbiana (Van Soest, 1994, Detmann et al., 2009). Considerando altos volumes consumidos do suplemento do Protocolo 2 é possível que tenha ocorrido a redução do consumo de volumoso. De acordo com Goularte et al. (2011) o fornecimento de concentrados farelados em grandes volumes podem reduzir o tempo de ruminação, enquanto o volumoso tende a aumentar o tempo de ruminação por grama de alimento. Segundo Ítavo et al. (2016) o fornecimento de suplementos com fontes de NNP com características de solubilidade média 
(ureia extrusada) no ambiente ruminal traz benefícios para terminação de bovinos Nelore a pasto desde que os custos relacionados a compra das fontes sejam eficientes. Para ganhos de peso de até $500 \mathrm{~g} \mathrm{dia}^{-1}$ e obrigatório o uso de fontes alternativas de proteína e energia (Simioni et al., 2009). O fornecimento recomendado possa variar entre $0,1 \%$ a $0,6 \%$ do peso corporal, de acordo com o objetivo e a disponibilidade de matéria seca (Ítavo et al., 2016). Cândido et al. (2015) a economicidade do sistema de terminação está relacionada a utilização de volumosos e concentrados.

\section{Conclusão}

A suplementação dos animais com protocolo 2 resultou em maior eficiência no desempenho, no entanto, a eficiência da conversão alimentar foi inferior e o maior fornecimento gerou uma receita total insuficiente para pagar os custos de produção, resultando em uma rentabilidade negativa devido ao gasto com suplementação no período experimental.

\section{Referências Bibliográficas}

Cândido, E. P., Santos, E. M., Ramos, J. P. d. F., Oliveira, J. S., Pinho, R. M. A., Perazzo, A. F., Ramos, R. C. S. \& Freitas, P. M. D. 2015. Economic response of feedlot sheep fed silages with different cultivars of sorghum. Ciência Rural, 45, 79-85.

Detmann, E., Paulino, M. F., Mantovani, H. C., Valadares Filho, S. C., Sampaio, C. B., Souza, M. A., Lazzarini, İ. \& Detmann, K. C. S. 2009. Parameterization of ruminal fibre degradation in low-quality tropical forage using MichaelisMenten kinetics. Livestock Science, 126, 136146.

Euclides, V. P. B., Euclides Filho, K., De Arruda, Z. J. \& Figueiredo, G. R. 1998. Desempenho de novilhos em pastagens de Brachiaria decumbens submetidos a diferentes regimes alimentares. Revista Brasileira de Zootecnia, 27, 246-254.

Ferreira, D. F. 2011. SISVAR: A Computer Statistical Analysis System. Ciência e Agrotecnologia, 35, 1039-1042.

Ferreira, I. C., Silva, M. A., Reis, R. P., Euclides Filho, K., Figueiredo, G. R., Fridrich, A. B., Corrêa, G. S. S., Valente, B. D. \& Felipe-Silva, A. S. 2005. Análise de sensibilidade da margem bruta da receita e dos custos do confinamento de diferentes grupos genéticos.
Arquivo Brasileiro de Medicina Veterinaria e Zootecnia, 57, 93-103.

Freitas, F. K., Rocha, M. G., Brondani, I. L., Restle, J., Neves, F. P., Roso, D. \& Costa, V. G. 2005a. Suplementação energética na recria de fêmeas de corte em pastagem cultivada de inverno. Dinâmica da pastagem. Revista Brasileira de Zootecnia, 34, 2029-2038.

Freitas, F. K., Rocha, M. G., Restle, J., Brondani, I. L., Macari, S., Guterres, É. P. \& Nicoloso, C. S. 2005b. Suplementação energética na recria de fêmeas de corte em pastagem cultivada de inverno. Produção animal. Revista Brasileira de Zootecnia, 34, 1256-1266.

Frizzo, A., Rocha, M. G. D., Restle, J., Montagner, D. B., Freitas, F. K. \& Santos, D. T. 2003. Suplementação energética na recria de bezerras de corte mantidas em pastagem de inverno. Revista Brasileira de Zootecnia, 32, 643-652.

Goularte, S. R., Ítavo, L. C. V., Ítavo, C. C. B. F., Dias, A. M., Morais, M. G., Santos, G. T. \& Oliveira, L. C. S. 2011. Comportamento ingestivo e digestibilidade de nutrientes em vacas submetidas a diferentes níveis de concentrado. Arquivo Brasileiro de Medicina Veterinária e Zootecnia, 63, 414-422.

Hellbrugge, C., Moreira, F. B., Mizubuti, I. Y., Prado, I. N., Santos, B. P. \& Pimenta, E. P. 2008. Steers performance grazing ryegrass (Lolium Multiflorum) with or without energetic supplementation. Semina: Ciências Agrárias, 29, 723-730.

Ítavo, L. C. V., Ítavo, C. C. B. F., Dias, A. M., Franco, G. L., Pereira, L. C., Leal, E. S., Araújo, H. S. \& Souza, A. R. D. L. 2016. Combinações de fontes de nitrogênio não proteico em suplementos para novilhos Nelore em pastejo. Revista Brasileira de Saúde e Produção Animal, 17, 448-460.

Lazzarini Neto, S. 1995. Controle Da Produção E Custos. São Paulo: Sdf Editores, (Coleção Lucrando Com A Pecuária, V.9).

Martin, N. B. et al. 1998. Sistema integrado de custos agropecuários - CUSTAGRI. Informações Econômicas, v. 28, n. 1, p. 7-28.

Moreira, F. B., Mizubuti, I. Y., Prado, I. N., Rocha, M. A., Ribeiro, E. L. A., Matsubara, M. T. \& Dognanil, R. 2006. Níveis de uréia em suplementos protéicos para novilhos mantidos em pastagem de capim Mombaça no inverno. Acta Scientiarium. Animal Sciences, 28, 63-71. 
Moreira, F. B. \& Prado, I. N. 2010. Sazonalidade na produção e qualidade de plantas forrageiras. In: Prado, I. N. (ed.) Produção de bovinos de corte e qualidade da carne. Eduem, Maringá, Paraná, Brasil.

NRC. 2000. Nutrient Requirements of Beef Cattle, 7th rev. edn. Natl. Acad. Press, Washington, DC, USA.

Prado, I. N. \& Moreira, F. B. 2002. Suplementação de bovinos no pasto $e$ alimentos usados na bovinocultura. Eduem, Maringá, Paraná, Brasil.

Prado, I. N., Moreira, F. B., Prado, R. M. \& Rotta, P. P. 2010. Alimentos usados para supelementação de bovinos de corte. In: Prado, I. N. (ed.) Produção de bovinos de corte e qualidade da carne. Eduem, Maringá, Paraná, Brasil.

Santos, M. E. R., Fonseca, D. M., Santos, T. G. B., Silva, S. P., Gomes, V. M. \& Silva, G. P. 2011. Morphogenic and structural characteristics of tillers on areas with signalgrass pasture varying on height. Revista Brasileira de Zootecnia, 40, 535-542.

SAS. 2004. SAS/STAT User guide, Version 9.1.2. SAS Institute Inc, Cary, NC, USA.

Simioni, F. L., Andrade, I. F., Ladeira, M. M., Gonçalves, T. M., Mata Júnior, J. I. \& Rodrigues, C. F. 2009. Níveis e frequência de suplementação de novilhos de corte a pasto na estação seca. Revista Brasileira de Zootecnia, 38, 2045-2052.

Van Soest, P. J. 1994. Nutritional ecology of the ruminant. Cornell University Press, Ithaca, NY, USA.

Article History:

Received 7 March 2017

Accepted 28 April 2017

Available on line 13 June 2017

License information: This is an open-access article distributed under the terms of the Creative Commons Attribution License 4.0, which permits unrestricted use, distribution, and reproduction in any medium, provided the original work is properly cited. 